\title{
Studies in organic archaeometry. VI' \\ Fat analysis sheds light on everyday life in prehistoric Anatolia: traces of lipids identified in chalcolithic potsherds excavated near Boğazkale, Central Turkey
}

\author{
Fritz Sauter,* Leopold Puchinger,* and Ulf-Dietrich Schoop** \\ * Vienna University of Technology, Getreidemarkt 9, A-1060 Vienna, Austria \\ E-mail: fsauter@pop.tuwien.ac.at; lpuching@mail.zserv.tuwien.ac.at \\ ** University of Tübingen, Schloss Hohentübingen, D-72070 Tübingen, Germany \\ E-mail: ulf-dietrich.schoop@uni-tuebingen.de
}

(received 06 June 03; accepted 02 Sept 03; published on the web 18 Sept 03)

\begin{abstract}
Ca 7500 years old potsherds stemming from a special type of jar were excavated in Central Anatolia. Upon chemical analysis traces of still remaining lipids were found: some fatty acids were identified, permitting the interpretation that the ancient content was a fat of animal origin, which can be considered as milk from ruminants or a dairy produce thereof. This result supports the archaeological hypothesis that such jars were used for the production of dairy produces, thus also giving some indication of the economic basis of chalcolithic life in this area.
\end{abstract}

Keywords: Archaeometry, prehistoric pottery, chalcolithic, capillary gas chromatography, lipids, fatty acids, milk

\section{General archaeological remarks}

The chalcolithic potsherds (dated ca. $5500 \mathrm{BC}$ ) which are studied in the present paper for possible traces of fat were excavated at the Central Anatolian site of Yarıkkaya, ${ }^{2}$ where in later times the famous Hittite capital Hattusha was located, near to the present town of Boğazkale. In contrast to the later Bronze Age times, when this region within the large bow of the ancient Halys river (now: Kizilırmak) was densely inhabited (probably mainly due to the occurrence of remarkable metal ore deposits), only small and scattered settlements are known in this area from chalcolithic times.

There are only very limited indications of the economy of chalcolithic settlements in this mountainous region which has been densely forested in prehistoric times, thus rendering all investigations on such topics even more interesting and important for the understanding of the past. 


\section{The archaeological problem to be dealt with}

It has been assumed - relying predominantly on indirect evidence - that the subsistence of the population living there in chalcolithic times was mainly based on secondary animal products, in particular on milk and on more durable products thereof which might also have been valuable as provisions for the cold time of the year. ${ }^{3}$

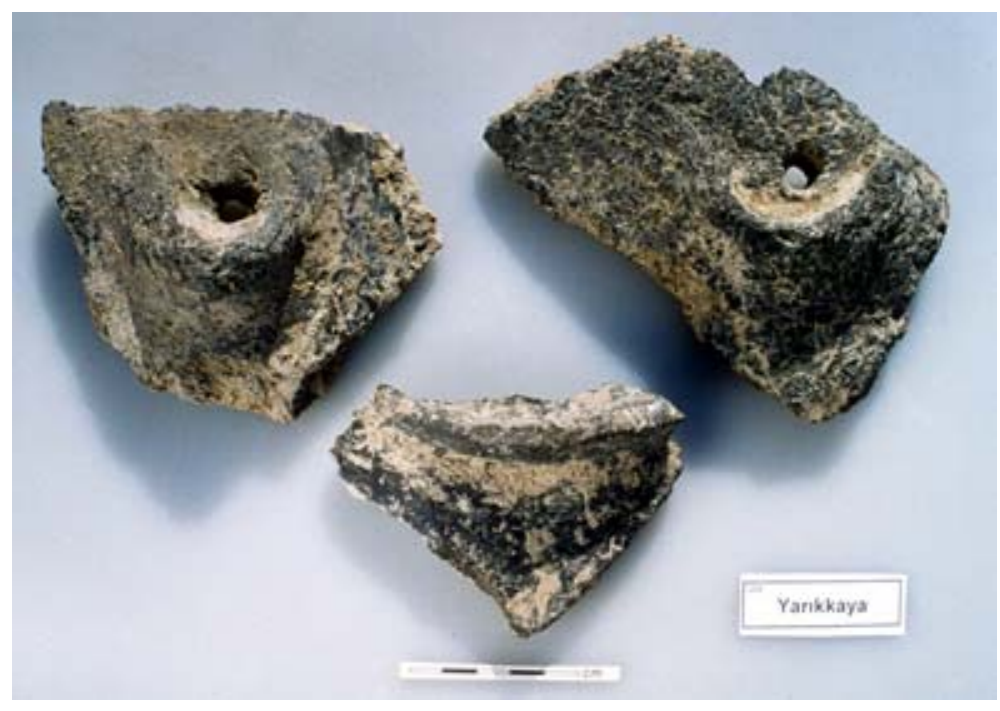

Figure 1. Chalcolithic potsherds from Yarkkaya, Turkey, showing the characteristic perforations and spouts.
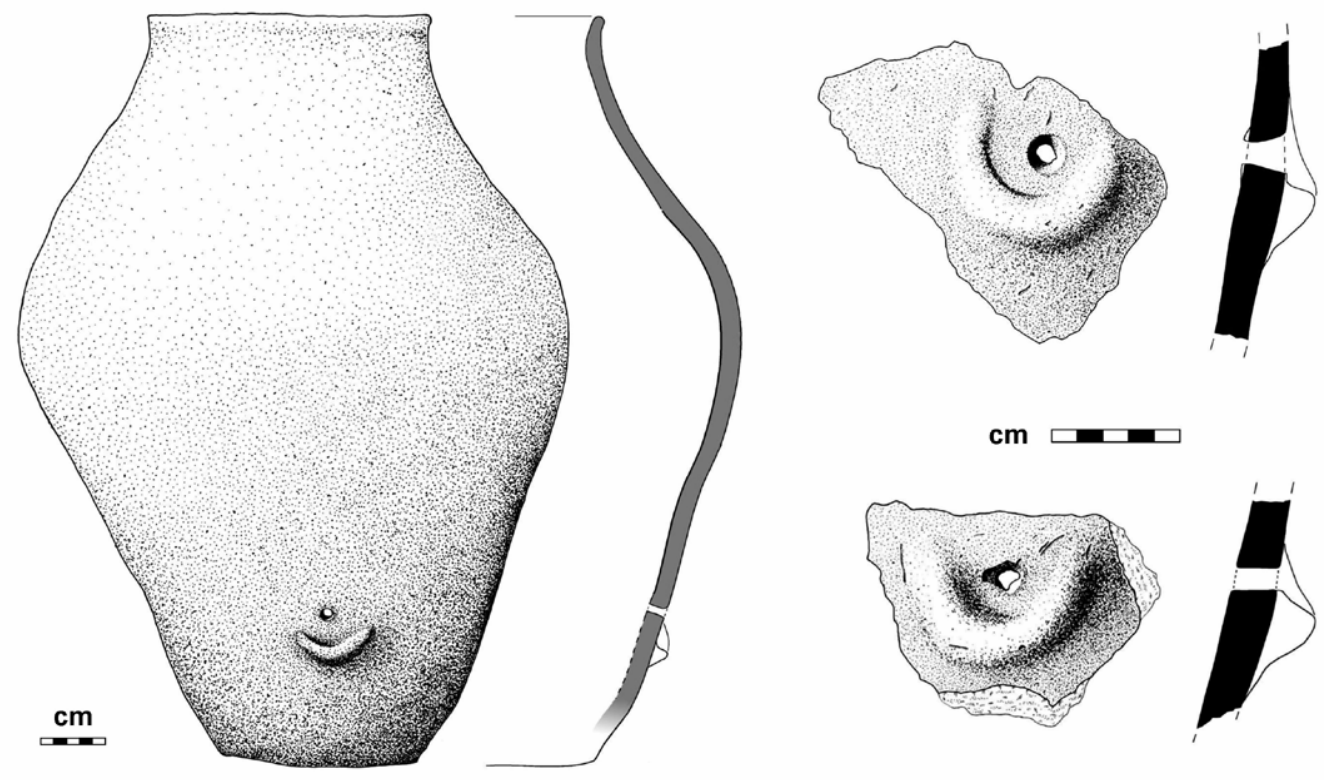

Figure 2. Drawings of a reconstructed jar and spouted fragments from Yarıkaya, Turkey. 
This hypothesis is strongly supported by the fact that such potsherds are belonging to a special type of jar which is frequently excavated at sites of this date, showing a circular hole in its lower part with a small spout underneath (Figures 1,2).

The possible ancient function of such vessels (Figures 2 and 3A) has tentatively been connected with the production of dairy produces ${ }^{3}$, interpreting them

either as something like a separatory funnel used in the course of the production of dairy produces,

or as a gadget applied similarly as traditional pottery churns (Figure 3B: Turkish taş yayık, still used in rural Anatolia in recent times) for the conversion of yoghurt into butter, whereby the small hole serves as an outlet to remove overpressure, while the main opening, i.e. the mouth of the jar, is closed in between by a piece of leather (since churning is done in a more or less horizontal position, the relative location of the hole is of minor importance).

At any rate, for both hypotheses a chemical identification of still remaining traces of animal fat in such prehistoric potsherds would be valuable, enhancing the probability that this special type of jar was really used for the production of a dairy produce, thus also shedding some more light on the economic basis of chalcolithic life in the mountainous areas of Central Anatolia.
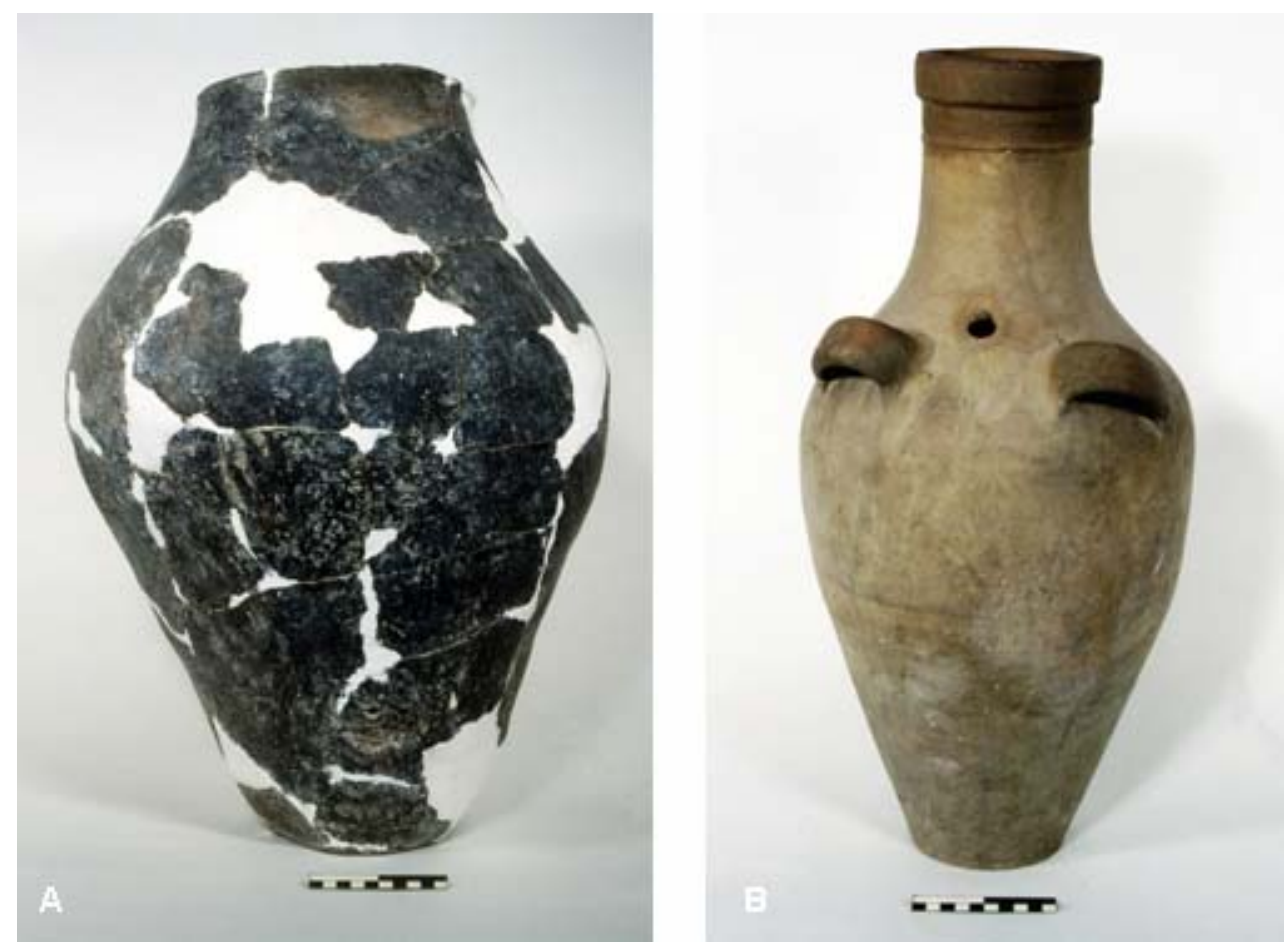

Figure 3. (A) Restored spouted jar from the chalcolithic settlement at Yarıkaya, Turkey. (B) Modern yaylk (pottery churn) from Central Anatolia. 


\section{Experimental Section}

The analytical methods described below are mainly based on the manuals published by Christie, ${ }^{4,5}$ but are partially adapted according to our particular interests.

\section{Samples}

For the analysis described below two pieces of chalcolithic potsherds stemming from two separate vessels were used. Both of them were originally located close to the hole mentioned above, and both were in original state (= not treated by restorers):

Sample 1: potsherd CAT $66(13 \mathrm{~g})$

Sample 2: potsherd CAT 66/Y3 (17 g)

Since a whole host of such potsherds was found in the course of these excavations, there was no need for the application of non-destructive analytical methods.

\section{Preparation of the solutions required for analysis}

\subsection{Solution for the determination of lipids soluble in organic solvents}

In order to extract such lipids (mainly still existing fats, i.e. glycerol still esterified with fatty acids) the finely pulverized potsherd $(3.0 \mathrm{~g})$ were treated twice with chloroform $(6 \mathrm{~mL})$ at room temperature in an ultrasonic bath for $15 \mathrm{~min}$. The extracts were combined and the solvent was evaporated by a mild stream of nitrogen gas; the residue was dissolved in toluene $(2 \mathrm{~mL})$.

\subsection{Solution for the determination of fatty acids existing in the samples as salts}

After chloroform extraction (cf. to 2.1.) the remaining residue (mainly inorganic material) was dried and acidified by dropwise addition of $2 \%$ phosphoric acid (ca. $20 \mathrm{~mL}$ ); this was monitored by a $\mathrm{pH}$ meter. The remaining residue plus the above acidic solution were extracted three times in a separatory funnel with $n$-hexane (totaling ca. $50 \mathrm{~mL}$ ). The organic extract was dried over $\mathrm{Na}_{2} \mathrm{SO}_{4}$ and evaporated to dryness. Conversion of the free fatty acids into their methyl esters was achieved by dissolving the residue in petroleum ether $(2 \mathrm{~mL})$ and by adding $\mathrm{BF}_{3} \cdot \mathrm{MeOH}(0,5 \mathrm{~mL}$; Supelco cat. no. 33021), keeping the reaction mixture at $80{ }^{\circ} \mathrm{C}$ for $10 \mathrm{~min}$. Subsequently, the solution of the methyl esters was shaken with distilled water $(1 \mathrm{~mL})$ to destroy excess of $\mathrm{BF}_{3}$; the aqueous layer was extracted again three times with petroleum ether (boiling range $60-80{ }^{\circ} \mathrm{C}$, in total ca. $10 \mathrm{~mL}$ ). Upon drying over $\mathrm{Na}_{2} \mathrm{SO}_{4}$ the combined organic solution was used as such for capillary gas chromatography.

2.3. Solution for the determination of those fatty acids which were originally (mainly) contained as unhydrolyzed glycerol esters (fats)

The toluene solution $(2 \mathrm{~mL})$ obtained according to 2.1. was heated with $\mathrm{MeONa}(0.5 \mathrm{~N}, 1.0 \mathrm{~mL}$; Supelco cat. no. 33080 ) at $80^{\circ} \mathrm{C}$ for $20 \mathrm{~min}$, thus effecting a base-catalyzed conversion into the corresponding methyl esters. Upon addition of water $(1 \mathrm{~mL})$ the aqueous layer was separated and repeatedly extracted with $n$-hexane and the organic layer was dried over $\mathrm{Na}_{2} \mathrm{SO}_{4}$ to become applicable to capillary gas chromatography. 


\section{Capillary gas chromatography}

Equipment: Carlo Erba Vega Series 6000.

Fused Silica Capillary Column DB 225 (J \& W Scientific, Folsom, C.A., USA), 30m x 0.25mm, film thickness $25 \mu \mathrm{m}$.

Carrier gas: He; pressure (column head): $180 \mathrm{kPa}$.

Injector and Detector Temp: $260^{\circ} \mathrm{C}$.

Mode: splitless.

Injection volume: $2.3 \mu 1$.

Multistage oven program: $90{ }^{\circ} \mathrm{C}(4 \mathrm{~min})$, st heating rate up to $160^{\circ} \mathrm{C}\left(10^{\circ} \mathrm{C} / \mathrm{min}\right.$.), 2nd heating rate up to $220^{\circ} \mathrm{C}\left(5^{\circ} \mathrm{C} / \mathrm{min}\right.$.), holding temperature: $220^{\circ} \mathrm{C}(7 \mathrm{~min})$.

\section{Analytical Results}

\section{General Results}

Traces of lipids could be extracted from both potsherds, containing unhydrolyzed lip(o)ids (mainly triglycerides) as well as free fatty acids (mainly existing as salts).

\section{Detailed Results}

Although capillary gas chromatography also showed peaks corresponding to fatty acids with lower and higher carbon numbers, the following discussion is restricted to fatty acids occurring in larger quantities, i.e., from $\mathrm{C}_{12}$ to $\mathrm{C}_{18}$. The values given in Table 1 refer to the relative percentages of these fatty acids, thus allowing the total always to add up to $100 \%$. As usual in lipid chemistry the designations of fatty acids given below are indicating the number of carbon atoms and the number of double bonds.

Table 1. Fatty acids identified in lipids originally existing in form of their salts and as triglycerides (fats)

\begin{tabular}{ccccc}
\hline & & $\begin{array}{c}\text { Sample 1 } \\
\text { from fats }\end{array}$ & $\begin{array}{c}\text { Sample 2 } \\
\text { from fats }\end{array}$ & $\begin{array}{c}\text { Sample 1 } \\
\text { from salts }\end{array}$ \\
\hline C12:0 & lauric acid & $5,9 \%$ & $17,8 \%$ & $1,1 \%$ \\
C14:0 & myristic acid & $4,5 \%$ & $10,3 \%$ & $3,1 \%$ \\
C14:1 & myristoleic acid & $2,2 \%$ & $4,0 \%$ & \\
C16:0 & palmitic acid & $27,2 \%$ & $25,4 \%$ & $29,2 \%$ \\
C18:0 & stearic acid & $44,3 \%$ & $11,0 \%$ & $54,9 \%$ \\
C18:1 & oleic acid & $15,9 \%$ & $31,5 \%$ & $11,7 \%$ \\
\hline
\end{tabular}




\section{Discussion}

The following statements can be made:

$>\quad$ It is obvious that the potteries in question - being untreated by restorers upon excavation - got in touch with fatty material already in prehistoric times.

$>\quad$ The lipids found contained triglycerides (i.e., unhydrolyzed fats) as well as free fatty acids (existing in the potsherds as salts), which obviously resulted from hydrolytic degradation of fats or related lipoids.

$>\quad$ Of course, palmitic acid and stearic acid were predominant, but oleic, lauric, myristic and myristoleic acids were also identified in lesser quantity.

Since the analytical data obtained from an only limited number of samples require a rather careful interpretation, and because the differences between the values of our two samples are considerable, we did not dare to apply the ratio of palmitic to stearic acid for drawing further conclusion, as was successfully done by Bourgeois and Gouin ${ }^{6}$ for prehistoric pottery from Harappa and by Kimpe and coworkers ${ }^{7}$ for Roman cooking pots.

The presence of myristic acid (C14:0), above all found in remarkable quantity in sample 2 (potsherd CAT 66/Y3) is a strong indication ${ }^{8,9}$ for an animal origin of this lipid.

The presence of lauric acid (C12:0), once again found in particularly high quantity in sample 2 (potsherd CAT 66/Y3), is not only one more indication ${ }^{8}$ of animal origin, but also for milk fats and/or derivatives thereof.

$>\quad$ Although some more analytical data would be desirable for an unequivocal assignment of these lipids to a well-defined genus of ruminants, the presence of the myristoleic acid (C14:1) as found in both samples can be considered ${ }^{9}$ as indicative of milk lipids stemming - at least to some part - from cattle and/or (with lower probability) from goat.

The fact that the fatty acid patterns from the two samples are differing remarkably regarding some of the components can certainly be interpreted as a consequence of many different - but additionally acting - reasons (e.g., differing degradation conditions acting on the two different vessels). One more conceivable reason could be that the two vessels originally contained differing mixtures of milk from possible ruminants (goats, sheep and cows).

At any rate, further and more comprehensive studies (including the identification of sterols as well as of additional fatty acids) will be carried out as soon as more archaeological samples will be available, thus permitting to supplement the present preliminary results.

\section{Summary}

Two potsherds excavated at the chalcolithic site of Yarkkaya near Boğazkale in Central Anatolia were analysed for traces of fats. 
Indeed in both of the two potsherds undecomposed fats (triacylglycerols) as well as fatty acids (stemming from complex lipids and remaining mainly as salts) could be isolated and studied.

Some well-defined fatty acids were identified by extraction, followed by hydrolysis and capillary gas chromatography of their methyl esters.

The mere occurrence of some of these fatty acids as well as their relative quantity allowed the interpretation that the ancient content of these clay vessels consisted of animal fat, with high probability of milk or a dairy product stemming from ruminants.

These analytical results shed some more light on the economical mainstay of Central Anatolia's prehistoric population some 7500 years ago.

\section{References}

1. (a) Sauter, F.; Jordis, U.; Graf, A.; Werther, W.; Varmuza, K. ARKIVOC 2000, (v), 735.

(b) Sauter, F.; Puchinger, L.; Graf, A.; Thumm, D. ARKIVOC 2001, (iii), 22.

(c) Sauter, F.; Graf, A.; Hametner, C.; Fröhlich, J. $\operatorname{ARKIVOC~2001,~(v),~} 21$.

(d) Sauter, F.; Graf, A.; Hametner, C.; Fröhlich, J.; Neugebauer, J.-W.; Preinfalk, F. ARKIVOC 2002, (i), 35. (e) Sauter, F.; Varmuza, K.; Werther, W.; Stadler, P. ARKIVOC 2002, (i), 54.

2. For details about the Yarkkaya excavations, see Hauptmann, H. Die Grabungen in der prähistorischen Siedlung auf Yarıkkaya, In Bittel, K.; Güterbock, H. G.; Hauptmann, H.; Kühne, H.; Neve, P.; Schirmer W.; Boğazköy IV. Funde aus den Grabungen 1967 und 1968; Mann: Berlin, 1969, pp 66.

3. (a) Schoop, U.-D. Unpublished Ph.D. Thesis, University of Tübingen, Germany, 2002. (b) Schoop, U.-D. Arkeoloji ve Sanat (Istanbul) 1998, 87, 26.

4. Christie, W. W. Manual 1982 "Lipid Analysis”; Pergamon Press: Oxford, 1982.

5. Christie, W. W. Manual 1989 "Gas Chromatography and Lipids"; The Oily Press: Ayr, Scotland, 1989.

6. Bourgeois, G.; Gouin, P. Paléorient 1955, 21/1, 125.

7. Kimpe, K.; Jacobs, P. A.; Waelkens, M. Journal of Chromatography A 2002, 968, 151.

8. Agozzino, P.; Avellone, G.; Donato, I. D.; Filizzola, F. Journal of Mass Spectrometry 2001, $36,443$.

9. Souci, S. W. Manual 1987, Fachmann, W.; Kraut, H. Eds. Der kleine Souci, Die Zusammensetzung der Lebensmittel; Wissenschaftliche Verlags-Ges.: Stuttgart, 1987. 